Erde war vorher calcinirt, dann ausgewaschen worden, um alle löslichen Stoffe zu entfernen, wurde vor Neuem calcinirt, über Schwefelsäure abgekühlt und in poröse Gefässe gebracht.

Die den Pflanzen zugefuihrte Luft strich durch Schwefelsäure und durch kohlensaures Natron vor dem Eintritt in die Glocke. Die Luft wurde durch Druck, nicht durch Aspiration hinein getrieben, um jede Feblerquelle zu vermeiden. Die aus Samen unter diesem Apparate gezogenen Pflanzen entwickelten sich bis zu einem gewissen Puncte und zeigten eine beträchtliche Lebenszähigkeit, die jungen Pflanzen absorbirten beim Wachsen die stickstoffhaltigen Stoffe der absterbenden alten. Leguminosen gingen bald nach der Keimung ein, sie konnten nicht ohne Stickstoff in Verbindung existiren. Während der ganzen Dauer der Versuche zeigte sich ein Verlust an Stickstoff, der als Ammoniak durch den Luftstrom aus dem Apparate entführt wurde. (Journ. de Phavm. et de Chim. Oct. 1863.)

Dr. Reich.

\title{
Reinigung des sublimirten Salmiaks, von Crace Calvert.
}

Der sublimirte Salmiak des Handels ist fast immer mit Eisenchlorür verunreinigt, das während der Sublimation aus dem Chloreisenammoniak sich bildet. Man reinigt das eisenhaltige Salz, indem man vor der Sublimation 5 Proc. trocknen sauren phosphorsauren Kalk oder 3 Proc. phosphorsaures Ammoniak zusetzt. Fs bildet sich dann aus dem Eisenchlorür nicht-flüchtiges Eisenphosphat. (Journ. de Pharm. d'Anvers. Juin 1863.) Dr. Reich.

\section{Bestimmung der salpetrigen und der Salpetersăure.}

Die von Harcourt vorgeschlagene Methode ist eine Modification, wonn nicht eine Vervollständigung der Methode von Schulze, die darin besteht, die Stickstoffverbindung durch Wasserstoffgas zu reduciren, das durch Einwirkung von Zink auf Aetzkalilauge entwickelt wird. Harcourt engt die Flïssigkeit auf ein kleines Volumen ein, bringt 2 oder $3 \mathrm{Grm}$. eines Gemenges von $2 \mathrm{Th}$. granulirtem Zink und 1 Th. vorher geglühter Eisenfeile mit 5-6 CC. concentrirter Aetzkalilösung zusammen und erhitzt zum Sieden. Das Ammoniak, welches sich zugleich mit den Wasserdämpfen entwickelt, ist ziemlich concentrirt, wie z. B. nach der Methode von Boussingault, und wird in einer titrirten Flïssigkeit von Oxalsäure 


\section{Bestimmung der Salpetersäzure mittelst Infusorienerde.}

oder Schwefelsäure mit einigen Tropfen Lackmus aufgefangen. Man erkennt das Ende der Operation daran, dass die aus dem Kühlapparate abfliessenden Tropfen der condensirten Dämpfe die in dem Recipienten befindliche geröthete Säure beim Durchgehen nicht mehr bläuen. Man titrirt danu die freie Säure durch eine titrirte alkalische Flüssigkeit. Harcourt zieht es vor, Zink gemeinschaftlich mit Eisen anzuwenden, weil er bemerkt zu haben glaubt, dass Zink allein nicht so wirksam sei.

Diese Methode ist auf die meisten Stickstoffsalze anwendbar; bei dem salpetersauren Bleioxyd erhält man jedoch keine genügenden Resultate, indem sich nicht alle Salpetersäure desselben in Ammoniak überführen lässt.

5 Milligrm. Salpeter gaben genügend Ammnniak, um geröthetes Lackmus zu bläuen. Ein empfindlicheres Reagens ist Quecksilberjodid-Jodkalium. Wenn der anmoniakalische Dampf in ein wenig schwacher Salzsäure aufgefangen ist, sättigt man mit Kali und fügt einen Tropfen des Jodsalzes hinzu; es bildet sich ein rother Niederschlag, der noch deutlich ist, wenn die ammoniakalische Flüssigkeit von der Behandlung von 0,001, 0,0005 selbst 0,0001 Salpeter herrührte. (Journ. de Pharm. et de Chim. Aout 186.3.)

Dr. Reich.

\section{Vieber die Bestimmung der Salpetersänre mittelst Infusorienerde.}

H. Rose's bewährte Methode, die Salpetersäure mittelst Glühens des völlig trocknen salpetersauren Salzes mit der 4-6 fachen Menge gereinigter Infusorienerde zu bestimmen, ist von Gräger mit einer kleinen Abünderung versehen worden. Diese besteht darin, dass die nit Säure gereinigte und geschlämmte Infusorienerde nach dem Trocknen mit gleichem Gewichte doppelt chromsauren Kalis innig gemengt und das Gemenge geglüht wird. Hierdurch wird jede Spur von noch etwa vorhandener Kohle zerstört. Das Gemenge ist auch weniger voluminös, für salpetersaures Kali reichen $3 \mathrm{Th}$. desselben auf $1 \mathrm{Th}$. des letzteren hin, für salpetersaures Natron die vierfache Menge. Ein viertelstündiges Gliihen des Gemenges aus Salpeter, zweifach-chromsaurem Kali und Infusorienerde reichte vollkommen hin, um die vollkommene Zersetzung zu bewirken.

Dagegen ist es Gräger nicht gelungen, Salpeter 